\title{
7 Advanced Syntax and Primary Pragmatics in Children With ASD
}

Difficulties with communication are one of the defining characteristics of autism spectrum disorder (ASD), whereas language abilities vary. Language, however, encompasses a vast array of knowledge. Lexical knowledge includes, for example, the ability to comprehend and produce a single vocabulary item, such as the verb kick. To learn this word, the language-learning child must categorize it as a verb and work out its meaning (e.g., to strike out with a foot). If she wishes to use this verb to refer to a past event, this requires morphological knowledge, such that as a regular verb, it takes the suffix -ed in the past tense. However, to use this word in a sentence, the child must also understand its syntactic properties. Kick, for example, needs an object, as well as a subject. This rudimentary syntactic knowledge will prevent her

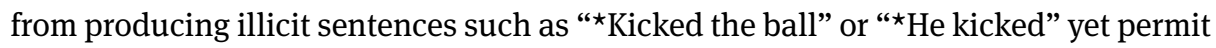
"He kicked the ball." On the basis of these simple examples, language appears to use literal knowledge and a predictable rule-based set of skills. However, if we return to the simple declarative, "He kicked the ball," we can see that a listener cannot lean on any aspect of linguistic knowledge mentioned so far to establish the reference of the pronoun. Lexical and morphological knowledge indicate that a singular male subject is intended, but that is all, and syntactic knowledge does not contribute anything in this respect. To recover the pronoun's reference (i.e., its antecedent), attendance to the context in which the sentence is uttered is required. When people go beyond so-called computational components of language to work out who is being referred to, they are using pragmatic knowledge. This pragmatic skill enables them to choose a referent based on the degree of context provided. Sometimes the referent will be unequivocally linked to one antecedent (perhaps only one person has been mentioned in the preceding discourse), but on other occasions, several possible referents might be available so the listener must make a decision, somehow attributing the contenders with different weights in terms of the likelihood of their being the intended referent.

The current study taps precisely into this skill. We compare examples of language (shown in examples 1 and 2 below), that might be expected to cause children with ASD difficulty. The difficulty is anticipated because the sentences call on either quite advanced syntactic knowledge, as in (1), or syntactic and pragmatic knowledge, as in (2), to work out who is being referred to in the bracketed clause. (1) and (2), for example, comprise a main clause and an embedded clause that lacks an overt subject. Additionally, (2) requires the use of contextual knowledge 
to resolve who is reading the book, that is, to assign a reference to the agent of the verb, "read."

1. Harry persuaded Hermione [to drink the potion]. Who drank the potion?

2. [Reading the book slowly] made the class sleepy. Who read the book?

Because the reference resolution in (2) is context mediated, it is an example of pragmatic processing. However, because it depends on a less complex set of inferences than for those used in irony interpretation, for example, it is often referred to as primary pragmatics. Primary pragmatics refers to the path to literal interpretations, such as in reference assignment or disambiguation, in which a person does not need to go beyond the truth conditions to arrive at the intended meaning (see Carston, 2002; de Villiers, Stainton, \& Szatmari, 2007; Recanati, 2004). Our focus on this less complex stage of pragmatic processing will enable us to identify pragmatic strengths in this population.

Having introduced some of the fundamental building blocks to linguistic knowledge, we can situate the topic of this chapter in relation to the two separate linguistic components: advanced syntax and primary pragmatics in children with ASD. In the next sections, we focus on one example of each of these with a view to drawing a comparison between the comprehension of typically developing (TD) children and children with ASD. The relevant examples belong to a set of constructions called control constructions, which is a term used for a heterogeneous set of sentences. All of them call on quite sophisticated syntactic knowledge, and some require primary pragmatic knowledge as well for the arguments (i.e., the subjects or objects) within them to be assigned a correct reference. It is rare to find a set of constructions that can track the step between syntax and pragmatics so neatly, which makes them particularly interesting for ASD. There is a great deal of literature on the more basic building blocks of language in ASD (Bartak, Rutter, \& Cox, 1975; Bartolucci, Pierce, \& Streiner, 1980; Eigsti \& Bennetto, 2009; Eigsti, Bennetto, \& Dadlani, 2007; Kjelgaard \& Tager-Flusberg, 2001; Tovar, Fein, \& Naigles, 2015; Walenski, Mostofsky, \& Ullman, 2014; see also Naigles \& Fein, Chapter 3, this volume; Naigles \& Chin, 2015), whereas work on syntax is only recently receiving sustained attention (e.g., Goodwin, Fein, \& Naigles, 2012; Janke \& Perovic, 2015; Perovic, Modyanova, \& Wexler, 2013a, 2013b; Riches, Loucas, Baird, Charman, \& Simonoff, 2010). The results of these recent studies suggest that some examples of syntax do create acquisition problems for different subtypes within ASD and remind us of the vital importance of keeping the heterogeneity of this disorder at the forefront of any research.

Work on pragmatics in ASD has a much longer trajectory (Baron-Cohen, 1988; Happé, 1993; Norbury, 2005), yet most attention has been focused on deficits in initiating and maintaining conversational interactions (see Boucher, 2009; TagerFlusberg \& Anderson, 1991) as well as understanding and use of figurative language, which calls on quite an advanced set of pragmatic skills: on metaphor (e.g., Dennis, 
Lazenby, \& Lockyer, 2001; Norbury, 2005; for a comparison between metaphor and metonymy, see Rundblad \& Annaz, 2010a, 2010b), irony (e.g., MacKay \& Shaw, 2004; Martin \& McDonald, 2004) and humor (e.g., Ozonoff \& Miller, 1996; see also Whyte \& Nelson, 2015, for findings from a standardized test involving instances of both figurative language and appropriate language use in social contexts). Deriving scalar implicatures has been reported not to be problematic, however (for comprehension of the quantifier some, see Pijnacker, Hagoort, Buitelaar, Teunisse, \& Geurts, 2009; for the scalar term or, see Chevallier, Wilson, Happé, \& Noveck, 2010). If the distinction between primary and secondary pragmatics is pertinent to ASD, as argued by de Villiers, Stainton, and Szatmari (2007), the findings from the literature could be interpreted as if aspects of secondary pragmatic knowledge, such as figurative language, ${ }^{1}$ or conversational implicatures, are more susceptible to deficiency in ASD than primary pragmatic knowledge. In this chapter, we extend and modify the existing profile by concentrating on the far less studied area of primary pragmatics. By looking at examples of control where the relevant argument's reference must be recovered pragmatically, our understanding of one of the first steps involved in pragmatic inference will be improved. An increased understanding of the earlier stages of pragmatics will make it possible to identify the point at which problems with contextual cues in ASD truly begin. Researchers and clinicians can then incorporate and build on the pragmatic strengths that exist in this population, perhaps thereby finding ways of rendering the more advanced examples of pragmatics less of a leap for the child.

In the next section, we explain what control constructions are, elaborating on the earlier examples introduced in (1) and (2), drawing a distinction between the syntactically regulated example (obligatory control) and its pragmatically regulated counterpart (nonobligatory control). With their properties clear, we move on to the interpretative issues they present and build on recent research on obligatory control in high-functioning children with ASD (Janke \& Perovic, 2015). This leads to the innovation of the current study in which we compare the referent choice of TD children and children with ASD in three examples of control under three conditions: one in which the critical sentences are presented in isolation (no prime), a second in which a topic of discourse is weakly established before the critical sentences (weak prime), and a third in which a topic is strongly established before the critical sentences (strong prime). Our aim is to draw a comparison between our two populations' attention to pragmatic cues. Specifically, we wish to find the point at which their choice of referent in control constructions is affected by cues that prime particular arguments in those sentences. If this aspect of pragmatics is intact in our children with ASD, we expect no significant difference between our two populations.

1 See Carston (2007) for arguments that metaphor should be seen as belonging to primary rather than secondary pragmatic knowledge. 


\section{Control}

Control constructions in English vary widely in their linguistic properties; however, they are all made up of at least a main clause and an embedded clause. The embedded clause, which is nonfinite (i.e., the verb inside it occurs in its gerund -ing form) or infinitival (the relevant verb is in its bare form preceded by to), has an understood, yet phonetically silent, subject. In the literature, this unpronounced subject is often called an empty category $(e c)$, which is the term we adopt here in our examples. The $e c$ 's reference can be recovered from a number of sources. Sometimes there is no choice, and its reference is restricted to a particular antecedent in the main clause. This may be the subject, as in (3a), or the object, as in (3b). The control relation is between the antecedent in the main clause (underlined), and the understood subject in the embedded clause, where the former "controls" the interpretation of the latter. When the interpretation of the $e c$ is restricted to a designated argument in the main clause, the control relation is called obligatory. Thus the sentences in (3) are examples of obligatory control (i.e., Harry is the only candidate for feeding the owl, and Hermione for drinking the potion).

3. a. Harry tried [ec to feed the owl].

b. Harry persuaded Hermione [ec to drink the potion].

In other types of control, the reference of the ec exhibits flexibility in its interpretation in that its reference can be linked to one of several arguments in the main clause. In (4a), for example, either the subject or the object can be understood as the agent in the embedded clause, even though people often demonstrate a strong preference for one (usually the object) over the other in the absence of any guiding context (see Janke, 2013). ${ }^{2}$ Because of the possibility of a "long-distance" reading of the $e c$, namely, that an object reading may be skipped in favor of the "farther away" subject reading, this type of control is called long-distance control.

4. a. Harry said to Luna that [[ec flying the broom upside down] was a great trick].

There are also examples of control where the choice of the ec's referent is between a sentence-internal referent or an unmentioned sentence-external one. In (4b), the most easily inferred agent of read in the bracketed verbal gerund is the class, the members of which are engaged in a collective reading activity. This is called a sentence-internal

2 In this example, there are other options in terms of referent choice, namely, both the subject and the object, someone else, or an arbitrary one, where the ec is interpreted generically. These possibilities are not discussed here because the experiment we conduct focuses only on the interpretation in which a choice between the subject and the object needs to be made. We return to how this is achieved later. 
referent reading. Given sufficient context, however, we could also infer an unmentioned agent, such as an unfortunate pupil, picked out by the teacher to read aloud to the rest of the class, which would be a sentence-external referent reading. This type of control is a controlled verbal-gerund subject.

4. b. [ec Reading the book slowly] made the class sleepy.

There are further differences between and within these constructions, as well as many more types of control, but on the basis of the three illustrated here, we can separate them into two main categories: those whose interpretations are constrained structurally and those who are not. The labels used to describe these categories are obligatory control (OC), represented by ( $3 a$ and $3 b$ ) and nonobligatory control (NOC), as in (4a) and (4b). This demarcation captures the fact that in the first group, the reference of the $e c$ is linked to a designated controller, whereas in the second, there is a choice to be made with respect to reference assignment, where pragmatic factors regulate that choice.

One of the key pragmatic factors determining the choice of referent in NOC is topichood. The topic of a sentence is informally described by the concept of aboutness (see Reinhart, 1981). In English, the topic often coincides with the subject (Givón, 1983; Reinhart, 1981). Thus in (5), "John” is the preferred topic.

5. John met Peter at the library.

However, topic is a discourse-based notion rather than a grammatically based one, and as such, new discourse can shift the topic to another argument. One way of doing this is to precede the critical sentence with one that promises to introduce a new topic in the forthcoming discourse, as in (6).

6. This story is about Peter. John met Peter at the library.

The topic-led interpretation of the ec in NOC constructions can be further demonstrated by switching or introducing new topics with increasing degrees of strength (see Bresnan, 1982).

Note what happens to the interpretation of our original example in (4b), if a forthcoming topic is weakly established, as in (7), or strongly established, as in (8).

7. This story is about Ron. ec Reading the book slowly made the class sleepy.

8. Ron is learning a new poem. Ron says each word bit by bit. ec Reading the book slowly made the class sleepy.

The degree of interpretative shift is linked to the strength of the pragmatic lead, where the weakly established topic in (7) has less of an effect than the strongly 
established one in (8). We refer to the former as a weak prime and the latter as a strong prime. The same effect is visible in long-distance control. Depending on a person's original preference in the baseline example in (4), this initial preference can gradually be switched by priming whichever of the arguments was their least preferred choice, as in (9) and (10).

9. This story is about Harry/Luna. Harry said to Luna that ec flying the broom upside down was a great trick.

10. Harry/Luna is testing his/her flying skills. Harry/Luna takes off in the air. Harry said to Luna that ec flying the broom upside down was a great trick.

Note that neither a weak or strong prime can interfere with judgments of OC because this relation is set within the grammar. In (11) and (12), the antecedent of the ec remains resolutely the object, namely, "Ron":

11. This story is about Hermione. Hermione persuaded Ron ec to bake the cake.

12. Hermione is having a party. Hermione makes all the party food. Hermione persuaded Ron ec to bake the cake.

The introduction of weak and strong topic primes provides a good way of testing whether children's acquisition of OC is complete. Once fully developed, their grammar should not permit a subject referent for this example, no matter how strong the contextual cue. To our knowledge, there is no work that has looked at the referent choices made by children with ASD in NOC under any conditions. Our interest is whether children with ASD will make similar topic-based choices to children without ASD. In the next subsection, we summarize briefly what is known about OC in children with ASD. This previous research on OC serves as a precursor to the current investigation into primary pragmatics in this population. Once we have established that their underlying syntax is intact, we can progress to a consideration of primary pragmatics, confident that any problems observed are not due to an impoverished syntax.

\section{Control in Typical Development and ASD}

TD children start producing OC structures at around age 3 years (see Broihier \& Wexler, 1995; Guasti, 2002; Sherman \& Lust, 1993). Despite this early production, comprehension is not adult-like for a few more years because some children continue to accept an illicit referent in OC environments (see Broihier \& Wexler, 1995; Eisenberg \& Cairns, 1994; Lust, Solan, Flynn, Cross, \& Schuetz, 1986; Cairns, McDaniel, Hsu, \& Rapp, 1994; Tavakolian, 1978).

Building on this literature with TD children, Janke and Perovic (2015) conducted a first study on the comprehension of OC in high-functioning children with ASD (HFA). 
They focused on examples of subject- and object-oriented OC, similar to those introduced in (3), with a view to assessing whether children (aged between 7 and 16 years) would permit illicit referents in single-complement subject control, as in (13a) or object control, as in (13b).

13. a. Homer tried [ec to wash Bart].

b. Marge persuaded Homer [ec to drive the car].

The results showed that the children performed excellently on these types of grammatically regulated control as well as the fillers, and there were no significant differences between these conditions or between the ASD group and two TD groups, one matched on nonverbal MA to the ASD group and the other on verbal MA. The results of this first study demonstrated that canonical OC, as an example of complex syntax, is right on track in children with ASD who are further classified as HFA.

There is far less acquisition literature on NOC in TD children (see Adler, 2006; Goodluck, 1987; Tavakolian, 1978). Adler (2006) investigated verbal gerund subject control, as introduced in (4b), in TD children, aged 3 to 6 years. She found that, contrary to adults, who base their interpretations of these on the topic of discourse, very young children are strongly biased toward the external referent. This is in line with early literature on the acquisition of similar constructions, which indicates that children aged 5 to 6 years opt more frequently for an external referent than a sentenceinternal one (Goodluck, 1987), a pattern that might indicate an immature grammar which has not yet restricted them to the sentence-internal referent, namely, the topic in the sentence. The TD children in our current investigation are much older (mean age 9.5 years), so we anticipated an effect of topic against which to compare the children with ASD (see Janke, in press).

In the next section, we turn to this first study, testing both OC and NOC in children with ASD, where we examine their interpretation of three examples of control under different amounts of discourse pressure: object control (OC), shown in (3b); controlled verbal gerund subjects (VGS), as in (4b); and long-distance control (LDC), illustrated in (4a). Specifically, we investigate the influence of topic on their interpretations of these constructions and compare their choices with those of a group of 14 nonverbal and verbal MA-matched TD children. The children will be presented with the constructions in three conditions: no prime, weak prime (weakly established topic), and strong prime (strongly established topic). We have seen that children with ASD are generally reported as having deficient pragmatics. In this experiment, we demonstrate that one example of pragmatic knowledge in children with ASD is fully functioning. To anticipate, just like the TD children against whom they are matched, children with ASD are guided by the discourse topic to recover the reference of the null subject. Interestingly, they also know when to ignore it. When the pragmatic cues used to manipulate interpretation of the NOC constructions are applied to OC, the children's grammar constrains them and they are not steered away from the 
Tab. 7.1: Ages and Mean Scores (Standard Deviations) on Standardized Tests of Language and Cognition

\begin{tabular}{lcc}
\hline Group & ASD $(\boldsymbol{n}=\mathbf{1 4})$ & TD $(\boldsymbol{n}=\mathbf{1 4})$ \\
\hline Age in months & $160.14(16.08)$ & $115.93(25.54)$ \\
Age range in months & $140-197$ & $69-157$ \\
KBIT Matrices RS & $\mathbf{2 7 . 8 6 ( 5 . 3 3 )}$ & $\mathbf{2 7 . 5 0 ( 6 . 5 7 )}$ \\
KBIT Matrices SS & $91.71(15.26)$ & $108.21(14.63)$ \\
BPVS-II RS & $\mathbf{9 3 . 6 4 ( 1 7 . 0 9 )}$ & $\mathbf{1 0 2 . 5 0 ( 2 0 . 0 8 )}$ \\
BPVS-II SS & $78.70(14.67)$ & $110.79(13.26)$ \\
TROG-2 RS & $13.21(2.97)$ & \\
TROG-2 SS & $83(13.56)$ & \\
\hline
\end{tabular}

Note: The scores for the measures on which participants with autism were matched to controls are in bold. ASD = autism spectrum disorder; TD = typically developing; BPVS-II = British Picture Vocabulary Scales-Second Edition; KBIT = Kaufman Brief Intelligence Test; RS = raw score; SS = standard score; TROG-2 = Test of Reception of Grammar-Second Edition.

structurally determined antecedent. As such, it can be argued that this aspect of their grammar is adult-like.

\section{Discourse Effects on OC and NOC in HFA}

\section{Participants}

Twenty-eight ${ }^{3}$ children took part in the study: 14 children $^{4}$ clinically diagnosed with ASD (all boys) aged between 11.6 and $16.4(M=13.34)$ and 14 younger TD controls ( 4 girls), aged 5.7 to $13.8(M=9.66)$. Children with ASD all attended one of two specialist schools for children with ASD in London and Kent. The formal diagnosis of ASD, which was an entry requirement to the schools, was made on the basis of the Diagnostic and Statistical Manual of Mental Disorders (fourth ed., text rev.; American Psychiatric Association, 2000) or the International Classification of Diseases (10th rev.; World Health Organization, 1992). None had any hearing impairments or any accompanying neurological or genetic deficits. Details of their scores on measures of verbal and nonverbal abilities are given in Table 7.1. Their nonverbal IQ, as measured on the Matrices subtest of the Kaufman Brief Intelligence Test (KBIT) ranged between 70 and 111, $M=91.71(S D=15.26$;

3 An additional four children with ASD were recruited, but three were excluded for failing to meet the threshold of 70 on nonverbal IQ, and for one child, no suitable match on nonverbal MA was found. 4 Five of these children also took part in Janke \& Perovic (2015) in their previous academic year at school, where they were tested on a different picture-selection task (using completely different drawings, e.g., the Simpson family) tapping into binding and obligatory control. 
to be classified as HFA, we include only children whose nonverbal IQ was 70 and higher, see, e.g., Howlin, 2003). Their scores on standardized tests of verbal abilities were more heterogeneous, in line with the literature (e.g., Kjelgaard \& Tager-Flusberg, 2001): On British Picture Vocabulary Scales-2 (BPVS-2), they ranged from 54 to $105, M=78.79$ ( $S D=14.67$ ), and on Test of Reception of Grammar-2 (TROG) from 55 to 106, $M=83$ $(S D=13.56)$. Typical controls with no known developmental delays or hearing impairments were recruited from schools in greater London. They were matched to the children with ASD on nonverbal MA (no statistically significant differences between groups on raw scores of the Matrices subtest on the KBIT, $p=.517$ ) and verbal MA (no statistically significant differences between groups on raw scores on BPVS-2, $p=.322$ ).

\section{Task}

We used a two-choice picture-selection task, a method widely used in the literature with school-age TD children and children with developmental disorders with and without intellectual impairment (e.g., Perovic et al., 2013a; Ring \& Clahsen, 2005). Four examples of control were included in the experiment, but here we report on the three introduced earlier, OC, LDC, and VGS. From the two pictures, children were asked to choose the one that best matched the sentence they heard. Item presentation was randomized automatically for each participant, and location of the correct picture balanced throughout (left or right). Task demands were reduced by limiting characters to four from the Harry Potter series (Harry, Ron, Hermione, and Luna), recognizable to children of all ages. Children were nevertheless familiarized with them during the introductory session. Two filler conditions, one using an embedded sentence and the other a simple SVO sentence preceded by a strong prime, were also included. Each construction included six trials in each condition. Thus, the OC and VGS constructions in three conditions (no prime, weak prime, and strong prime), the LDC in five conditions (no prime, weak prime of object, weak prime of subject, strong prime of object, and strong prime of subject), plus the two filler conditions translated into 78 trials in total. The stimuli were presented on a laptop computer and randomized by a computer program, over three testing sessions, within 7 to 10 days of each other.

\section{Sentence Types}

(Object Control) Hermione persuaded Ron to bake the cake.

The OC construction used pictures in which the character represented by the matrix object engaged in an action while the character represented by the matrix subject stood by. The foil depicted the matrix subject engaging in the action. For the preceding example sentence, the corresponding picture showed "Ron" baking the cake, with "Hermione" standing next to him, whereas the foil showed "Hermione" baking the cake, with "Ron" standing next to her. 
(Verbal Gerund Subject) Reading the book slowly made Hermione sleepy.

The VGS pictures showed the sentence-internal referent engaged in an action, with the sentence-external character next to him or her. The alternative picture depicted the sentence-external referent engaging in the action instead. To clarify, in the preceding example, the picture corresponding to an interpretation in which "Hermione" is reading, showed "Ron" and "Hermione" sitting on the sofa, with "Hermione" holding a book having fallen asleep, whereas the picture corresponding to the interpretation in which "Ron" is reading, showed "Ron" holding the book, with "Hermione" having fallen asleep next to him.

(Long-Distance Control) Harry said to Luna that flying the broom upside down was a great trick.

LDC had one picture in which the character represented by the matrix object engaged in an action, while the matrix subject stood by, and a second, where the characters' actions were reversed. In the example sentence above, the picture corresponding to "Harry" being the agent of fly had "Harry" flying the broomstick, with "Luna" standing by, whereas the picture corresponding to "Luna" as the agent of fly, had "Luna" flying and "Harry" standing by.

These same pictures were used for all three conditions: no prime; weak prime, in which a topic is introduced before the critical sentence, as shown in (7), (9), and (11); and strong prime, in which a topic is introduced and then reinforced before the critical sentence, as illustrated in (8), (10), and (12).

\section{Results}

Each experimental condition included three different verbs $\times$ two repetitions, amounting to six trials in each one. For OC and LDC, the responses were summed up according to the number of times the object was chosen as the referent, which gave a 7-point scale, ranging from 0 to 6 . Comparisons focused on the degree to which the children's initial preferences for the subject or object could be altered as a function of the primes. For VGS, responses were summed according to the number of times the internal referent was chosen. This also gave a 7-point scale ranging from 0 to 6 . These comparisons focused on the degree to which their initial preferences for the internal-external referent could be altered as a function of the primes. Both groups scored at ceiling on the two filler conditions (embedded subject-verb-object [SVO] and SVO preceded by a strong prime), which were excluded from further analysis.

\section{Obligatory Control}

We first looked at both groups' object responses in OC across the three conditions: no prime, weak prime, and strong prime. The medians for both groups' preference for the 


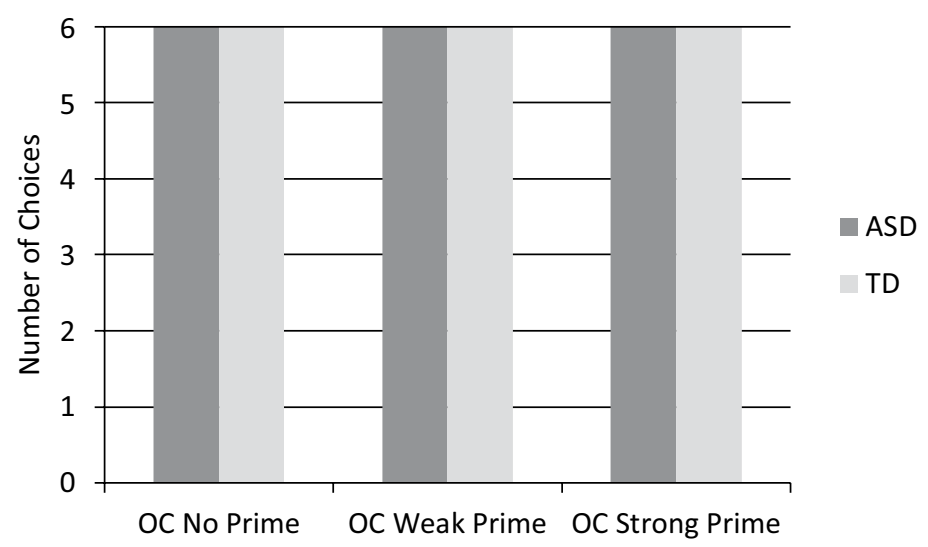

Fig. 7.1: Median number of object choices in obligatory control (OC). ASD = children with autism spectrum disorder; TD = typically developing children.

matrix object as the antecedent of the $e c$ in the infinitival complement were uniform in all three conditions: 6, 6, 6 (the only appropriate answer in this condition). Two Friedman's tests conducted on the TD group's responses to OC across the three conditions and the ASD group's responses across the three conditions were not significant, demonstrating that neither of the groups was affected by either of the primes. Figure 7.1 illustrates the uniformity of the children's responses across the three conditions.

\section{Verbal Gerund Subjects}

Comparisons on TD children's responses to VGS revealed an effect of the primes on referent choice. Their preference for the internal referent in the baseline condition switched to the external referent in both the weak and strong prime conditions (Mdns: 4, 0, 0). A Friedman test conducted on their scores across the three conditions was significant $(p<.001)$. Three Wilcoxon tests (Bonferroni adjusted) compared responses in the no prime condition versus the weak prime condition, the no prime condition versus the strong prime condition, and the weak prime condition versus the strong prime condition. The first two were significant $(p<.001$ and $p<.001$ ), and the last was not. This showed that both the weak primes and the strong primes swayed TD children's interpretations toward the topic. The absence of a difference between the weak and strong primes can be sourced to the strength of the weak prime, rendering the strong prime effect undetectable.

The same comparisons were conducted on the ASD group. In the baseline condition in which there was no prime, children with ASD were split between choosing the internal or external referent. The addition of the weak and strong prime, however, steered them unequivocally toward the external referent, as indicated by the median 


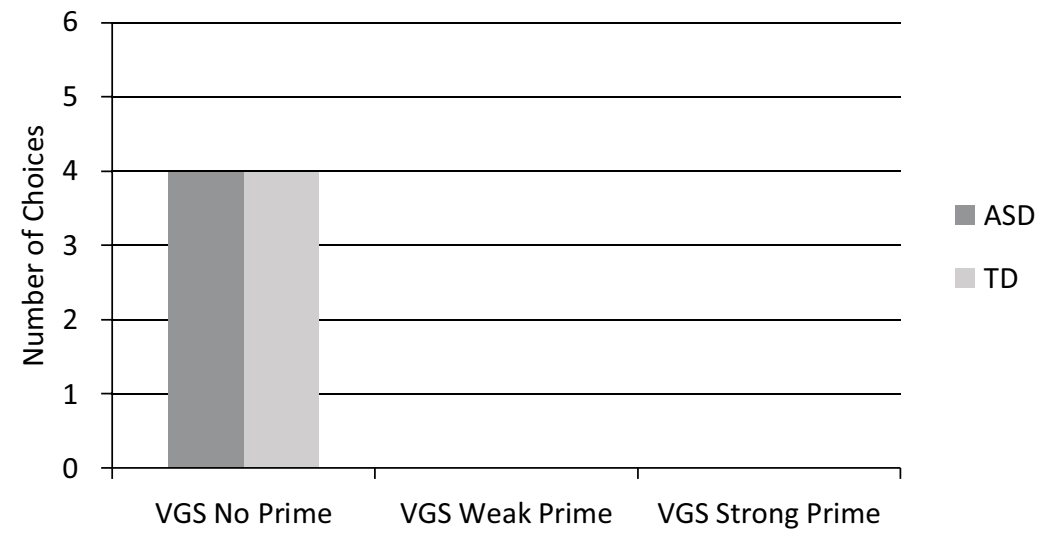

Fig. 7.2: Median number of internal referent choices in verbal gerund subjects (VGS). ASD $=$ children with autism spectrum disorder; TD = typically developing children.

values, which, like the TD children, were 4, 0, 0. The Friedman test conducted on their scores across the three conditions was significant $(p=.003)$. Three Wilcoxon tests compared responses in the no prime condition versus the weak prime condition, the no prime condition versus the strong prime condition, and the weak prime condition versus the strong prime condition. The first two were significant ( $p=.006$ and $p=.004$ ) and, as with the TD group, the last was not, which showed that both the weak and the strong primes guided children with ASD to the topic. These results across both groups are displayed in Figure 7.2.

\section{Long-Distance Control}

The focus of LDC was again the number of object-oriented interpretations across the three conditions. We first compared TD children's object responses in the no prime condition, the weak-prime-object condition and the strong-prime-object condition. As expected, TD children demonstrated a strong preference for the object in the baseline condition, which made the effect of topic less detectable (Mdns: 5, 5, 6); this was confirmed by a Friedman test, which did not reach significance. We then compared TD children's object responses in the no prime condition, the weak-prime-subject condition and the strong-prime-subject condition. If a prime effect were to be visible, it was predicted to be in this condition, given the children's preference for an objectoriented reading in the baseline condition. The medians indicated an effect of the strong prime (Mdns: 5, 5, 2), which was supported by a Friedman test ( $p=.006$ ). Two Wilcoxon tests were conducted to confirm that the source of the significance came from the strong-prime-subject condition. The comparison between the no prime condition and the weak-prime-subject condition was not significant, whereas for the 
comparison between the no prime condition and the strong-prime-subject condition was $(p=.009)$. Thus, although the weak prime of the subject did not cause the children to veer away from their baseline preference of the object, the strong prime did.

Our comparisons of the ASD group proceeded in the same way. We first compared children with ASD's object responses in the no prime condition, the weak-primeobject condition and the strong-prime-object condition. Children with ASD also demonstrated a preference for the object in the baseline condition (Mdns: 4, 5, 6), yet an effect of the strong prime could still be detected by a Friedman test $(p=.001)$. Three Wilcoxon tests were conducted to test the difference between the no prime condition and the weak prime of the object, the no prime condition and the strong prime of the object, and the weak and strong prime conditions. The first was not significant, but the latter two were ( $p=.007$ and $p=.01$, respectively). This demonstrates that although the weak prime of the object had no effect on choice, the strong priming of the object did. The significance of this, relative to the nonsignificance of it for TD children, can be sourced to the difference between the two group's baseline interpretations: TD children preferred the object in the baseline condition to a greater degree than children with ASD, who were more varied in their subjectand object-oriented interpretations in the baseline. We then compared the object responses of our participants with ASD in the no prime condition, the weak-primesubject condition, and the strong-prime-subject condition. The medians suggested a marginal move toward the topic (Mdns: 4, 3, 3), but a Friedman test was not significant. These results are displayed in Figure 7.3.

\section{Discussion}

The current study used a topic-based experiment to gain an initial insight into the reference assignment strategies in control of high-functioning children with ASD. We concentrated on three examples (object control, verbal-gerund-subject control, and long-distance control) and tested 28 children's interpretations of the ec under different strengths of discourse pressure. The main questions were whether their choices were affected by pragmatic leads and, if they were, whether they differed from TD children in terms of the strength of cue necessary before a significant shift in interpretation became visible. The results showed that contextual cues did not interfere with judgment on OC in either group. The results on NOC revealed different effects for control type but not for group. That is, both the weak and strong primes affected referent choice for the ec in VGS for both groups of children, but only the strong prime could affect their referent choice in LDC. We now consider these results in this order, establishing how they build on existing literature and the implications they have for the grammatical and pragmatic profile of children with ASD.

The results on OC are interesting in several respects. First, our ASD group performed excellently in the condition without any prime. We have thus supported the previous 
(a)

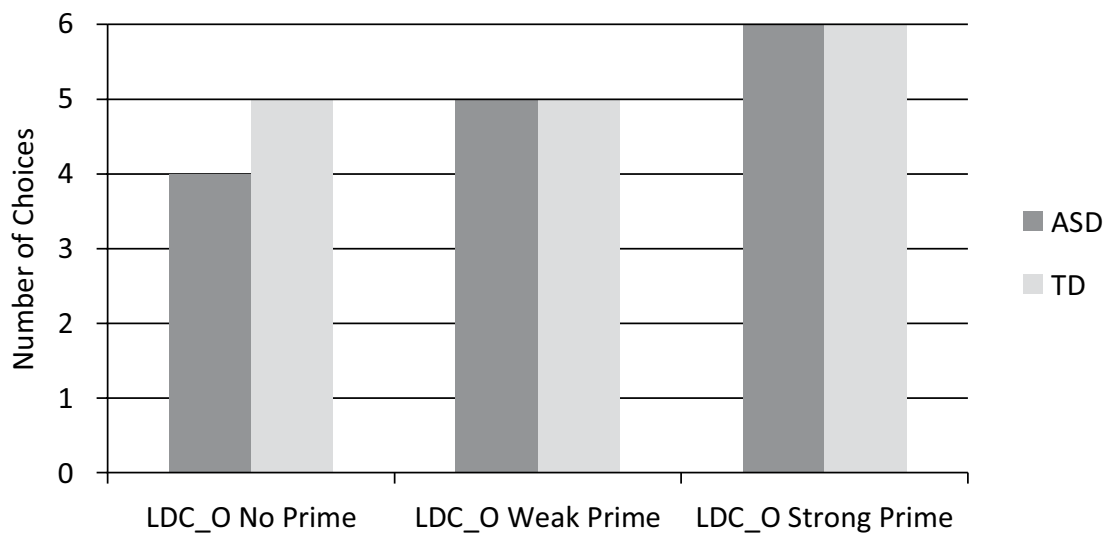

(b)

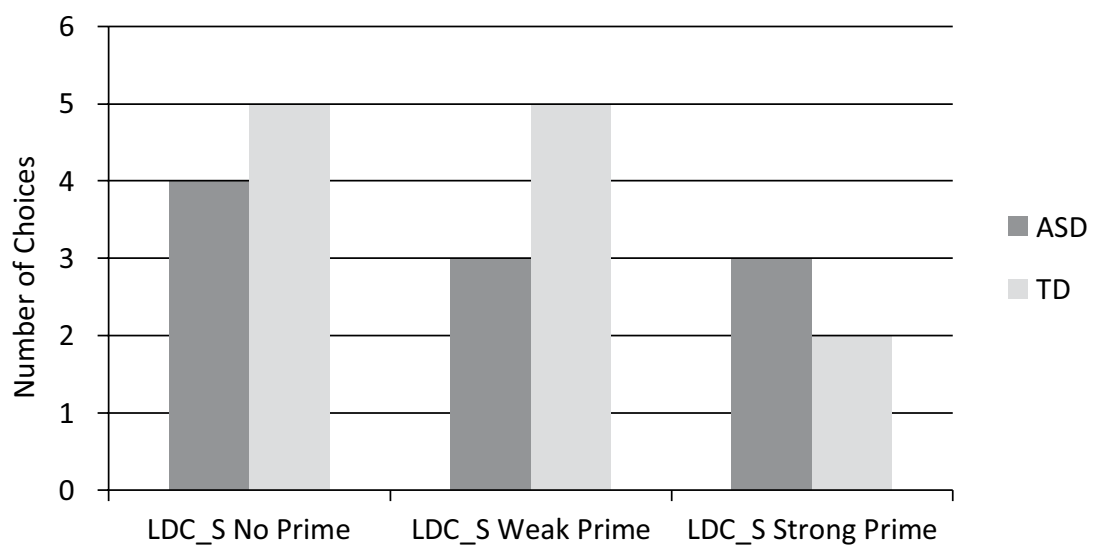

Fig. 7.3: (a) Median number of object choices in long-distance control (LDC) when object (0) is primed. (b) Median number of object choices in long-distance control (LDC) when subject (S) is primed. $A S D=$ children with autism spectrum disorder; $T D=$ typically developing children.

findings of Janke and Perovic (2015), which tested single-complement subject control (i.e., with try) and object control (i.e., with persuade) and found the constructions to be intact. Given the absence of any other literature on this example of advanced syntax in this population, our ability to replicate the absence of problems with OC in our current ASD group is important. We can now be more confident that OC is an example of complex syntax with which high-functioning children with ASD do not have difficulties. This forms an important contribution to the growing profile of syntactically based reference assignment in ASD. Work conducted by Perovic et al. (2013b), for example, has indicated that reference assignment in reflexive binding (i.e., "Bart washed himself") also seems unaffected in high-functioning children with 
ASD, where children comprehend that the reflexive, himself, is obligatorily linked to the most local referent, namely, Bart. This is in contrast to pronominal binding (i.e., "Bart washed him"), which goes beyond purely syntactic knowledge and was found to be more problematic for these children. Children with HFA were apt to accept illicit readings in which him and Bart co-refer. In contrast, children with ASD who were low functioning struggled with both constructions.

An addition in the current study was the inclusion of two priming conditions, which further corroborate that this aspect of syntax is adult-like in our population. Recall that young TD children may produce OC structures early, but their acquisition was shown not to be complete by comprehension studies that tested whether they would permit illicit referents. Specifically, for a few years after their first productions, some TD children permit incorrect referents in OC when prompted by a contextual cue. When children no longer allow their reference choices to be guided by the context in structures that are grammatically determined, this is a good indication that their grammar has converged with adult grammar for this construction. Our TD and HFA groups' consistent object-oriented interpretation of OC across all three conditions suggests that both groups of children have reached this point. In addition, the ASD group's $100 \%$ correct scores on the filler conditions, one of which also primed an illicit referent, buttress the demarcation they have drawn between grammatically and pragmatically determined reference relations. This argument of course depends on the children with ASD using the contextual cues in environments where they are warranted. As we now turn to NOC, we will see that they do.

In the VGS construction, the baseline condition has one referent, and this is sentence-internal. This referent, then, is also the topic of the sentence, rendering it, all else being equal, the preferred referent for the ec. In this particular task, however, where children are shown two pictures, a sentence-external referent is visually represented in the alternative picture. That is, for the trial "Pouring the water quickly made Luna wet," the children are shown one picture in which Luna is pouring the water, making herself wet with Harry standing next to her, and an alternative one in which Harry is pouring water and making Luna wet. This introduces a visual prompt absent from the sentence when seen or read out in isolation, and this was shown to influence both groups' choice of referent in the baseline condition. Contrary to adults, the majority of whom opt for the sentence-internal referent when reading the sentence without an accompanying picture, the children were split between an internal and external referent choice in this condition. Recall that the medians for an internal referent reading for both the TD and ASD group were 4, where the range was from 0 to 6 . The introduction of the weak prime, however, which introduced the external referent as the topic, reduced the medians in both the TD and ASD group to 0, a drop that was significant for both groups. This indicates that for TD children and children with ASD alike, a weakly established topic was a sufficiently strong cue to guide away from the sentence-internal referent to the sentence-external one: The topic decided the referent. Unsurprisingly, the strong prime, in which the topic was strongly established, 
also switched referent choice definitively. At this point, then, we have shown one example of NOC, whose ec's referent is topic-led in adult grammars (see Adler, 2006; Bresnan, 1982; Janke, 2007), to be topic-led in our group of children with ASD as well as the younger TD group against whom they were matched. If we contrast this result with our observations for OC, we now have evidence of their applying this discourse rule selectively and appropriately.

The second type of NOC we tested was long-distance control (LDC), which was also expected to exude discourse effects. However, there were properties that distinguished LDC from VGS, which might have interacted with the topic primes. In particular, in LDC, there are two arguments in the main clause that could serve as the antecedent for the ec in the embedded clause, as in (14), whereas in VGS control (15), there was only one.

14. Harry said to Luna that [(ec flying the broomstick upside down) was a great trick]. 15. [ec Pouring the water slowly] made Luna wet.

The availability of two arguments in LDC introduces some new factors that might influence referent preference. The two arguments serve different syntactic functions, for example, where one is the subject and one is the object. Subjects are more frequently associated with topichood, so the subject's potential topic status might give it precedence for some in the baseline condition and compete with the experimentally induced pragmatic leads in the primed conditions. Alternatively, the object is linearly (but not structurally) more local to the $e c$, which might be a contributory factor. Linear distance is relevant to the interpretation of other pragmatically regulated elements such as overt pronouns. This can be seen in (16), where there is a strong preference for the pronoun in the third sentence to refer to the last mentioned argument, namely, "Ron," as demonstrated by the less felicitous (17a) compared with (17b).

16. Harry looked at Ron. He had tripped over the fence.

17. a. Harry looked at Ron. \#He had tripped over the fence, and so had Ron. ${ }^{5}$

b. Harry looked at Ron. He had tripped over the fence, and so had Harry.

Given that there are some similarities between discourse-mediated pronouns and the $e c$ in NOC, linear distance might be another factor influencing referent choice, independent of topichood.

The results in LDC revealed topic effects for both groups, but only in the strong prime condition. TD children strongly preferred the object as the referent for the ec in the baseline condition, a fact that made the priming of the object fruitless. For this group, it was the priming of the subject that tested for the effect of topic on interpreta-

5 The hashtag (\#) symbol indicates when an interpretation is semantically anomalous. 
tion. These were significant only in the strong prime condition. For the ASD group, a slightly different pattern was observed. Although they, too, exhibited a preference for the object in the baseline condition, the strong priming of the object was significant. In contrast to the TD group, the strong priming of the subject did not yield a significant shift. There are a number of possible reasons for this. First, more children with ASD opted for a subject interpretation in the baseline than did the TD children, which might have contributed to masking the effect of the prime (as with the object prime for the TD children). Another possibility is that those children with ASD who preferred an object reading to begin with were reluctant to switch to a less local referent. In contrast, those who preferred a subject reading to begin with found it easier to be guided by the topic to the more local referent. This is an interesting issue, but one we leave for future research. What this second example of NOC has demonstrated, however, is that children with ASD required the same strength of pragmatic cue as their TD counterparts before switching from their initial interpretations, a finding that points to the children using this area of primary pragmatics in the same way as each other. In OC, when the TD children ignored the pragmatic cue, so did the ASD group. In VGS, when the TD children were guided by both cues, so were the children with ASD. Finally, when the TD children discerned between the two strengths of prime, ignoring the weak one but using the strong one, so did the children with ASD.

The broader relevance of this study is that it has focused on the point at which syntax and pragmatics meet, thereby isolating the first steps of pragmatic processing. It is an important addition to the aforementioned studies that have examined more complex examples of pragmatics, where the gap between what has been said and what is intended is much larger. We have demonstrated that one of the smaller inferential stages involved in pragmatic processing is intact, a skill that might be exploited for the more complex cases.

\section{Conclusion}

In this chapter, we have focused on an example of advanced syntax and an example of primary pragmatics (obligatory and nonobligatory control) to compare reference assignment in two language domains. We first showed that the performance of children with ASD on OC was flawless. This affirmative result substantiates our claim that certain complex syntactic dependencies are intact: The children understand the obligatory, structurally determined local relation between an antecedent and its dependent. These results contribute to current debate about which examples of advanced syntax are preserved in this population and which cause difficulty.

We then showed that the children's pragmatically mediated reference resolution with two examples of NOC patterned precisely with those of TD children. This will complement research on communicative ability in ASD so far, which, focusing extensively 
on the social requirements of communication (e.g., conversational turn-taking and reciprocity) and also advanced areas of pragmatics (e.g., that employed in figurative language), has reported major impairments. By tapping into children with ASD's comprehension in this far less charted domain, we hope a more precise profile of pragmatic ability will become possible. Viewed in the context of the few other studies on primary pragmatics (Chevallier et al., 2010; de Villiers et al., 2007; Pijnacker et al., 2009), a more positive picture is emerging. There are areas of pragmatics in which children with ASD excel-and these areas might just provide the stepping-stones to more complex pragmatic milestones.

\section{References}

Adler, A. (2006). Syntax and discourse in the acquisition of adjunct control (Doctoral dissertation). Massachusetts Institute of Technology, Cambridge, MA. Retrieved from https://dspace.mit.edu/handle/1721.1/37417

American Psychiatric Association. (2000). Diagnostic and statistical manual of mental disorders (4th ed., text rev.). Washington, DC: Author.

Baron-Cohen, S. (1988). Social and pragmatic deficits in autism: Cognitive or affective? Journal of Autism and Developmental Disorders, 18, 379-402. http://dx.doi.org/10.1007/BF02212194

Bartak, L., Rutter, M., \& Cox, A. (1975). A comparative study of infantile autism and specific developmental receptive language disorder. The British Journal of Psychiatry, 126, 127-145.

Bartolucci, G., Pierce, S., \& Streiner, D. (1980). Cross-sectional studies of grammatical morphemes in autistic and mentally retarded children. Journal of Autism and Developmental Disorders, $10,39-50$.

Boucher, J. (2009). The autistic spectrum: Characteristics, causes and practical issues. Thousand Oaks, CA: Sage.

Bresnan, J. (1982). Control and complementation. Linguistic Inquiry, 13, 343-434.

Broihier, K., \& Wexler, K. (1995). Children's acquisition of control in temporal adjuncts. In C. Schutze, J. Ganger, \& K. Broihier (Eds.), MIT Working Papers in Linguistics, 26. Cambridge, MA: MIT Press.

Cairns, H., McDaniel, D., Hsu, J., \& Rapp, M. (1994). A longitudinal study of principles of control and pronominal reference in child English. Language, 70, 260-288.

Carston, R. (2002). Thoughts and utterances. http://dx.doi.org/10.1002/9780470754603

Carston, R. (2007). How many pragmatic systems are there? In M. J. Frapolli (Ed.), Saying, meaning, referring: Essays on the philosophy of Francois Recanati (pp. 18-48). London, England: Palgrave Macmillan.

Chevallier, C., Wilson, D., Happé, F., \& Noveck, I. (2010). Scalar inferences in autism spectrum disorders. Journal of Autism and Developmental Disorders, 40, 1104-1117. http://dx.doi.org/ 10.1007/s10803-010-0960-8

Dennis, M., Lazenby, A. L., \& Lockyer, L. (2001). Inferential language in high-function children with autism. Journal of Autism and Developmental Disorders, 31, 47-54. http://dx.doi.org/10.1023/A:1005661613288

de Villiers, J., Stainton, R., \& Szatmari, P. (2007). Pragmatic abilities in autism spectrum disorder: A case study in philosophical and the empirical. Midwest Studies in Philosophy, 31, 292-317. 
Eigsti, I.-M., \& Bennetto, L. (2009). Grammaticality judgments in autism: Deviance or delay. Journal of Child Language, 36, 999-1021. http://dx.doi.org/10.1017/S0305000909009362

Eigsti, I.-M., Bennetto, L., \& Dadlani, M. B. (2007). Beyond pragmatics: Morphosyntactic development in autism. Journal of Autism and Developmental Disorders, 37, 1007-1023. http://dx.doi.org/ 10.1007/s10803-006-0239-2

Eisenberg, S. L., \& Cairns, H. S. (1994). The development of infinitives from three to five. Journal of Child Language, 21, 713-734. http://dx.doi.org/10.1017/S0305000900009521

Givón, T. (Ed.). (1983). Topic continuity in discourse: A quantitative cross-language study. Amsterdam, The Netherlands: Benjamins.

Goodluck, H. (1987). Children's interpretations of pronouns and null NPs: An alternative view. In B. Lust (Ed.), Studies in the acquisition of anaphora (Vol. 2, pp. 247-269). http://dx.doi.org/ 10.1007/978-94-009-3387-3_11

Goodwin, A., Fein, D., \& Naigles, L. R. (2012). Comprehension of wh-questions precedes their production in typical development and autism spectrum disorders. Autism Research, 5, 109-123. http://dx.doi.org/10.1002/aur.1220

Guasti, M. T. (2002). Language acquisition: The growth of grammar. Cambridge, MA: MIT Press.

Happé, F. G. E. (1993). Communicative competence and theory of mind in autism: A test of relevance theory. Cognition, 48, 101-119. http://dx.doi.org/10.1016/0010-0277(93)90026-R

Howlin, P. (2003). Outcome in high-functioning adults with autism with and without early language delays: Implications for the differentiation between autism and Asperger syndrome. Journal of Autism and Developmental Disorders, 33, 3-13. http://dx.doi.org/10.1023/A:1022270118899

Janke, V. (2007). Control without PRO. Doctoral dissertation, University College London, London, England.

Janke, V. (2013). The distribution of NOC and its + human restriction. In M. Kolokonte \& V. Janke (Eds.), Interfaces in language III (pp. 121-157). Newcastle upon Tyne, England: Cambridge Scholars.

Janke, V. (in press). Pragmatic leads and null subjects: When children consult leads and when they do not. Proceedings of the 40th annual Boston University Conference on Language Development. Somerville, MA: Cascadilla Press.

Janke, V., \& Perovic, A. (2015). Intact grammar in HFA? Evidence from control and binding. Lingua, 164, 68-86. http://dx.doi.org/10.1016/j.lingua.2015.06.009

Kjelgaard, M. M., \& Tager-Flusberg, H. (2001). An investigation of language impairment in autism: Implications for genetic subgroups. Language and Cognitive Processes, 16, 287-308. http://dx.doi.org/10.1080/01690960042000058

Lust, B., Solan, L., Flynn, S., Cross, C., \& Schuetz, E. (1986). A comparison on null and pronoun anaphora in first language acquisition. In B. Lust (Ed.), Studies in the acquisition of anaphora (Vol. 2, pp. 245-277). http://dx.doi.org/10.1007/978-94-009-4548-7_7

MacKay, G., \& Shaw, A. (2004). A comparative study of figurative language in children with autistic spectrum disorders. Child Language Teaching and Therapy, 20, 13-32. http://dx.doi.org/10.1191/0265659004ct2610a

Martin, I., \& McDonald, S. (2004). An exploration of causes of non-literal language problems in individuals with Asperger syndrome. Journal of Autism and Developmental Disorders, 34, 311-328. http://dx.doi.org/10.1023/B:JADD.0000029553.52889.15

Naigles, L. R., \& Chin, I. (2015). Language development in children with autism. In E. L. Bavin \& L. R. Naigles (Eds.), The Cambridge handbook of child language (2nd ed., pp. 637-658). http://dx.doi.org/10.1017/СВ09781316095829.029 
Norbury, C. (2005). The relationship between theory of mind and metaphor: Evidence from children with language impairment and autistic spectrum disorder. British Journal of Developmental Psychology, 23, 383-399. http://dx.doi.org/10.1348/026151005X26732

Ozonoff, S., \& Miller, J. N. (1996). An exploration of right-hemisphere contributions to the pragmatic impairments of autism. Brain and Language, 52, 411-434. http://dx.doi.org/10.1006/brln.1996.0022

Perovic, A., Modyanova, N., \& Wexler, K. (2013a). Comparisons of grammar in neurodevelopmental disorders: The case of binding in Williams syndrome and autism with and without language impairment. Language Acquisition, 20, 133-154. http://dx.doi.org/10.1080/10489223.2013.766742

Perovic, A., Modyanova, N., \& Wexler, K. (2013b). Comprehension of reflexive and personal pronouns in children with autism: A syntactic or pragmatic deficit? Applied Psycholinguistics, 34, 813-835. http://dx.doi.org/10.1017/S0142716412000033

Pijnacker, J., Hagoort, P., Buitelaar, J., Teunisse, J. P., \& Geurts, B. (2009). Pragmatic inferences in high-functioning adults with autism and Asperger syndrome. Journal of Autism and Developmental Disorders, 39, 607-618. http://dx.doi.org/10.1007/s10803-008-0661-8

Recanati, F. (2004). Literal meaning. Cambridge, England: Cambridge University Press.

Reinhart, T. (1981). Pragmatics and linguistics: An analysis of sentence topics. Philosophica, 27, 53-94.

Riches, N. G., Loucas, T., Baird, G., Charman, T., \& Simonoff, E. (2010). Sentence repetition in adolescents with specific language impairments and autism: An investigation of complex syntax. International Journal of Language \& Communication Disorders, 45, 47-60. http://dx.doi.org/10.3109/13682820802647676

Ring, M., \& Clahsen, H. (2005). Distinct patterns of language impairment in Down's syndrome and Williams syndrome: The case of syntactic chains. Journal of Neurolinguistics, 18, 479-501. http://dx.doi.org/10.1016/j.jneuroling.2005.06.002

Rundblad, G., \& Annaz, D. (2010a). The atypical development of metaphor and metonymy comprehension in children with autism. Autism, 14, 29-46. http://dx.doi.org/10.1177/1362361309340667

Rundblad, G., \& Annaz, D. (2010b). Development of metaphor and metonymy comprehension: Receptive vocabulary and conceptual knowledge. British Journal of Developmental Psychology, 28, 547-563. http://dx.doi.org/10.1348/026151009X454373

Sherman, J. C., \& Lust, B. (1993). Children are in control. Cognition, 46, 1-51. http://dx.doi.org/10.1016/0010-0277(93)90021-M

Tager-Flusberg, H., \& Anderson, M. (1991). The development of contingent discourse ability in autistic children. Journal of Child Psychology and Psychiatry, 32, 1123-1134. http://dx.doi.org/10.1111/j.1469-7610.1991.tb00353.x

Tavakolian, S. L. (1978). Children's comprehension of pronominal subjects and missing subjects in complicated sentences. In H. Goodluck \& L. Solan (Eds.), Papers in the structure and development of child language (UMASS Occasional Papers in Linguistics, Vol. 4, pp. 145-152). Amherst: University of Massachusetts.

Tovar, A. T., Fein, D., \& Naigles, L. R. (2015). Grammatical aspect is a strength in the language comprehension of young children with autism spectrum disorder. Journal of Speech, Language, and Hearing Research, 58, 301-310. http://dx.doi.org/10.1044/2014_JSLHR-L-13-0257 
Walenski, M., Mostofsky, S. H., \& Ullman, M. T. (2014). Inflectional morphology in high-functioning autism: Evidence for speeded grammatical processing. Research in Autism Spectrum Disorders, 8, 1607-1621. http://dx.doi.org/10.1016/j.rasd.2014.08.009

Whyte, E. M., \& Nelson, K. E. (2015). Trajectories of pragmatic and nonliteral language development in children with autism spectrum disorders. Journal of Communication Disorders, 54, 2-14. http://dx.doi.org/10.1016/j.jcomdis.2015.01.001

World Health Organization. (1992). The ICD-10 classification of mental and behavioural disorders: Clinical descriptions and diagnostic guidelines. Geneva, Switzerland: Author. 
